Article

\title{
Waste Cooking Oil as an Alternate Feedstock for Biodiesel Production
}

\author{
Arjun B. Chhetri ${ }^{1}$, K. Chris Watts ${ }^{2}$ and M. Rafiqul Islam ${ }^{1, *}$ \\ ${ }^{1}$ Civil and Resources Engineering Dalhousie University, Room D510, 1360 Barrington St., Box 1000, \\ Halifax, N.S. B3J 2X4, Canada; E-mail: kcarjun@gmail.com (for Arjun B. Chhetri) \\ 2 Process Engineering, Dalhousie University, Halifax, NS, Box 1000, Halifax, N.S. B3J 2X4, Canada; \\ Tel. (902) 494-3269; Fax 420-7639; E-mail: chris.watts@dal.ca
}

* Author to whom correspondence should be addressed; E-mail: rafiqul.islam@dal.ca

Received: 27 March 2008 / Accepted: 9 April 2008 / Published: 10 April 2008

\begin{abstract}
As crude oil price reach a new high, the need for developing alternate fuels has become acute. Alternate fuels should be economically attractive in order to compete with currently used fossil fuels. In this work, biodiesel (ethyl ester) was prepared from waste cooking oil collected from a local restaurant in Halifax, Nova Scotia, Canada. Ethyl alcohol with sodium hydroxide as a catalyst was used for the transesterification process. The fatty acid composition of the final biodiesel esters was determined by gas chromatography. The biodiesel was characterized by its physical and fuel properties including density, viscosity, acid value, flash point, cloud point, pour point, cetane index, water and sediment content, total and free glycerin content, diglycerides and monoglycerides, phosphorus content and sulfur content according to ASTM standards. The viscosity of the biodiesel ethyl ester was found to be $5.03 \mathrm{~mm}^{2} / \mathrm{sec}$ at $40^{\circ} \mathrm{C}$. The viscosity of waste cooking oil measured in room temperature (at $21^{\circ} \mathrm{C}$ ) was $72 \mathrm{~mm}^{2} / \mathrm{sec}$. From the tests, the flash point was found to be $164^{\circ} \mathrm{C}$, the phosphorous content was $2 \mathrm{ppm}$, those of calcium and magnesium were $1 \mathrm{ppm}$ combined, water and sediment was $0 \%$, sulfur content was $2 \mathrm{ppm}$, total acid number was $0.29 \mathrm{mgKOH} / \mathrm{g}$, cetane index was 61, cloud point was $-1^{\circ} \mathrm{C}$ and pour point was $-16^{\circ} \mathrm{C}$. Production of biodiesel from waste cooking oils for diesel substitute is particularly important because of the decreasing trend of economical oil reserves, environmental problems caused due to fossil fuel use and the high price of petroleum products in the international market.
\end{abstract}


Keywords: Waste cooking oil, alternate energy, biodiesel, feedstock, fuel characterization

\section{Introduction}

Increasing uncertainty about global energy production and supply, environmental concerns due to the use of fossil fuels, and the high price of petroleum products are the major reasons to search for alternatives to petrodiesel. Lean [1] claimed that the global supply of oil and natural gas from the conventional sources is unlikely to meet the growth in energy demand over the next 25 years. In this perspective, considerable attention has been given towards the production of biodiesel as a diesel substitute. Moreover, biodiesel fuel has become more attractive because of its environmental benefits [2], due to the fact that plants and vegetable oils and animal fats are renewable biomass sources. Biodiesel represents a largely closed carbon dioxide cycle (approximately 78\%), as it is derived from renewable biomass sources. Compared to petroleum diesel, biodiesel has lower emission of pollutants, it is biodegradable and enhances the engine lubricity [3] and contributes to sustainability $[3,4]$. Biodiesel has a higher cetane number than diesel fuel, no aromatics, no sulfur, and contains 10-11\% oxygen by weight [5].

Use of neat (unprocessed) vegetable oils in the compression ignition engines is reported to cause several problems due to its high viscosity [6]. Biodiesel which is accepted as an attractive alternative fuel, is prepared by transesterification of vegetable oils and animal fats with an alcohol in presence of a catalyst. However, the land use for production of edible oil for biodiesel feedstock competes with the use of land for food production. Moreover, the price of edible plant and vegetable oils is usually higher than petrodiesel. The use of waste cooking oil as biodiesel feedstock reduces the cost of biodiesel production [5] since the feedstock costs constitutes approximately 70-95\% of the overall cost of biodiesel production [7]. Hence, the use of waste cooking oils and non-edible oils should be given higher priority over the edible oils as biodiesel feedstock.

\subsection{Potential of waste cooking oil as a feedstock for biodiesel source}

Huge quantities of waste cooking oils and animal fats are available throughout the world, especially in the developed countries. Management of such oils and fats pose a significant challenge because of their disposal problems and possible contamination of the water and land resources. Even though some of this waste cooking oil is used for soap production, a major part of it is discharged into the environment. The Energy Information Administration in the United States estimated that some 100 million gallons of waste cooking oil is produced per day in USA, where the average per capita waste cooking oil was reported to be 9 pounds [8]. The per capita waste cooking oil production in Canada may be somewhat similar to that of the United States, hence for this study, it is assumed that the per capita waste cooking oil production to be 9 pounds per year. Statistics Canada [9] estimated the total population of Canada to be 33 million. Hence, the total waste cooking oil produced in Canada could be approximately 135,000 tons/year. In the EU countries, the total waste cooking oil production was approximately 700,000-1,000,000 tons/yr [10]. The UK produces over 200,000 tons of waste cooking oil per year [11]. As large amounts of waste cooking oils are illegally dumped into rivers and landfills, 
causing environmental pollution [12], the use of waste cooking oil to produce biodiesel as petrodiesel substitute offers significant advantages because of the reduction in environmental pollution.

Diesel fuel consumption significantly contributes to the formation of greenhouse gases (GHG) and other global pollutant emissions. Klass [13] pointed out that petroleum diesel is also the major source for the emission of NOx, SOx, CO, particulate matter and volatile organic compounds (VOCs). Emission of such pollutants not only has negative impacts to the global environment but also severe impacts in human health due to their persistence in the environment.

It is reported that Canada alone utilizes approximately 23 million tons of diesel annually and $46 \%$ of this is utilized in the transportation sector [10]. The global consumption of diesel fuel per year is approximately 934 million tons per year and the United States alone consumes 178 million tons of diesel fuel annually [14]. If Canada plans a 5\% mix in the total diesel consumption as a renewable portfolio standard (RPS) requirement, which is, approximately 1.15 million tons per year, a substantial portion of this requirement can be replaced by using biodiesel produced from waste cooking oil. The use of waste cooking oil as a biodiesel source has a potential to reduce $\mathrm{CO}_{2}$, particulate matter and other greenhouse gases as the carbon contained in biomass-derived fuel is largely biogenic and renewable.

Waste cooking oil, which is otherwise wasted, is one of the most economical choices to produce biodiesel. Since one of the major concerns on biodiesel production is the price of feedstock, utilization of waste cooking oil significantly enhances the economic viability of biodiesel production.

\section{Results and Discussion}

\subsection{Glycerin Separation and Biodiesel Washing}

Washing of final ester products is a very important activity during biodiesel processing. The ester was washed several times through the distilled water creating fine mist from the top through a spray. Kemp [15] reported that fine mist washing which makes less agitation resulting in less soap formation. Washing can improved by using hot wash water of $50-60^{\circ} \mathrm{C}[16]$.

\subsection{Conversion Efficiency and Effect of Catalyst Content}

The conversion of waste cooking oil to ester was monitored and samples were taken every 5 minutes for 20 minutes, when it was considered that the reaction was completed. The ester conversion was obtained from the Iatroscan analysis. Duplicate samples were taken and the average result was plotted (Figure 1). Conversion did not improve even after continuing the reaction after 20 minutes. The average overall conversion achieved was $94.5 \%$.

Issariyakul et al. [17] obtained an ethyl ester conversion of waste cooking oil up to $97 \%$. The oil contained approximately 5-6\% weight of free fatty acid. The authors carried out two stage acid and alkali catalyzed transesterification. Leung and Gau [18] reported that the conversion of waste cooking oil using sodium hydroxide catalysts was approximately $86 \%$. The physical and chemical properties of the oil feedstocks used by Leung and Gau [18] are shown in Table 1. 
Figure 1. Trend of ester conversion with time.

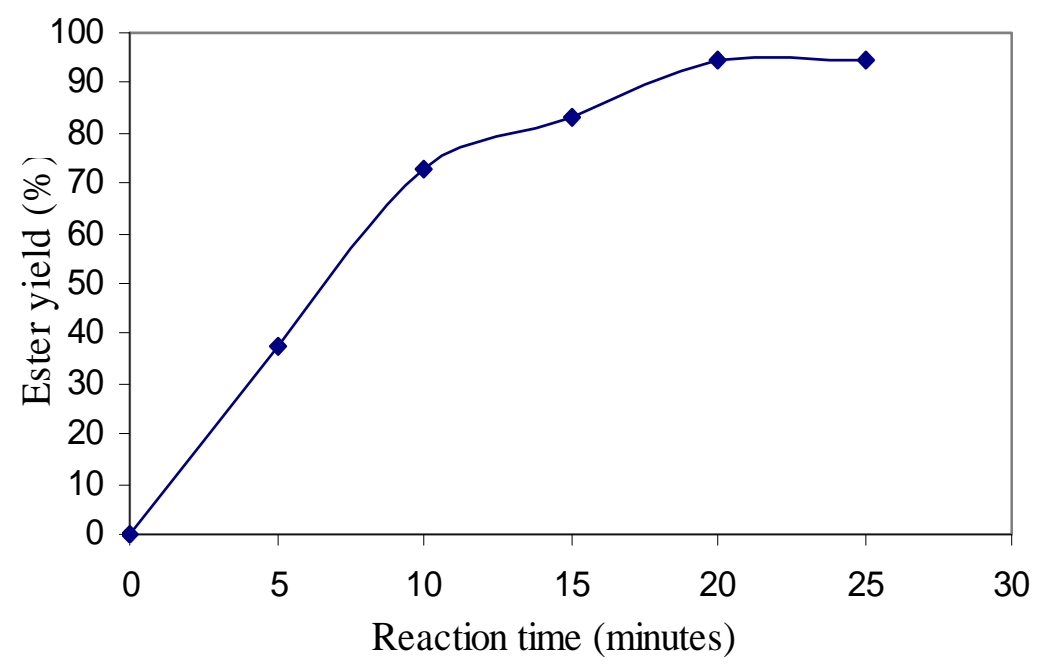

Table 1. Physical and chemical properties of oil feedstocks [18].

\begin{tabular}{|l|c|c|}
\hline Property & Waste cooking oil & Neat canola oil \\
\hline Acid value (mg KOH/g) & 2.1 & $<0.5$ \\
\hline Kinematic viscosity at 40ㄷ (cSt) & 35.3 & 30.2 \\
\hline \multicolumn{2}{|c|}{ Fatty acid composition (wt\%) } \\
\hline Myristic (C14:0) & 0.9 & 0.1 \\
\hline Palmitic (C16:0) & 20.4 & 5.5 \\
\hline Palmitoleic (C16:1) & 4.6 & 1.1 \\
\hline Stearic (C18:0) & 4.8 & 2.2 \\
\hline Oleic (C18:1) & 52.9 & 55 \\
\hline Linoleic(C18:2) & 13.5 & 24 \\
\hline Linolenic(C18:3) & 0.8 & 8.8 \\
\hline Arachidic (C20:0) & 0.12 & 0.7 \\
\hline Eicosenic (C20:1) & 0.84 & 1.4 \\
\hline Behenic (C22:0) & 0.03 & 0.5 \\
\hline Erucic (C22:1) & 0.07 & 0.4 \\
\hline Tetracosanic (C24:0) & 0.04 & 0.3 \\
\hline Mean molecular wt (g/mol) & 856 & 882 \\
\hline
\end{tabular}

Zheng et al. [19] showed that methyl ester conversion of waste cooking oil in acid catalyzed transesterifications can reach up to $99 \%$. This process was carried out using a very high methanol to oil ratio of 250:1.

Transesterification was carried out using $0.4 \%, 0.6 \%, 0.8 \%, 1.0 \%$ and $1.2 \%$ of catalyst concentration. With $0.4 \%$ of catalyst concentration, no reaction was observed as there was no separated layer of ester and glycerin. With the catalyst concentration of $0.6 \%, 0.8 \%$ and $1.0 \%$, ester 
yield were approximately 50\%, 94\% and 40\%, respectively (Figure 2). It was observed that the ester yield decreased with the increase in sodium hydroxide concentration. With $1.2 \%$ catalyst concentration, a complete soap formation was observed. This is because the higher amount of catalyst caused soap formation [20]. The rise in soap formation made the ester dissolve into the glycerol layer. Triplicate samples were used and the maximum standard deviation from the mean was found to be approximately $4 \%$.

Figure 2. Conversion efficiency of ester under different catalysts concentration.

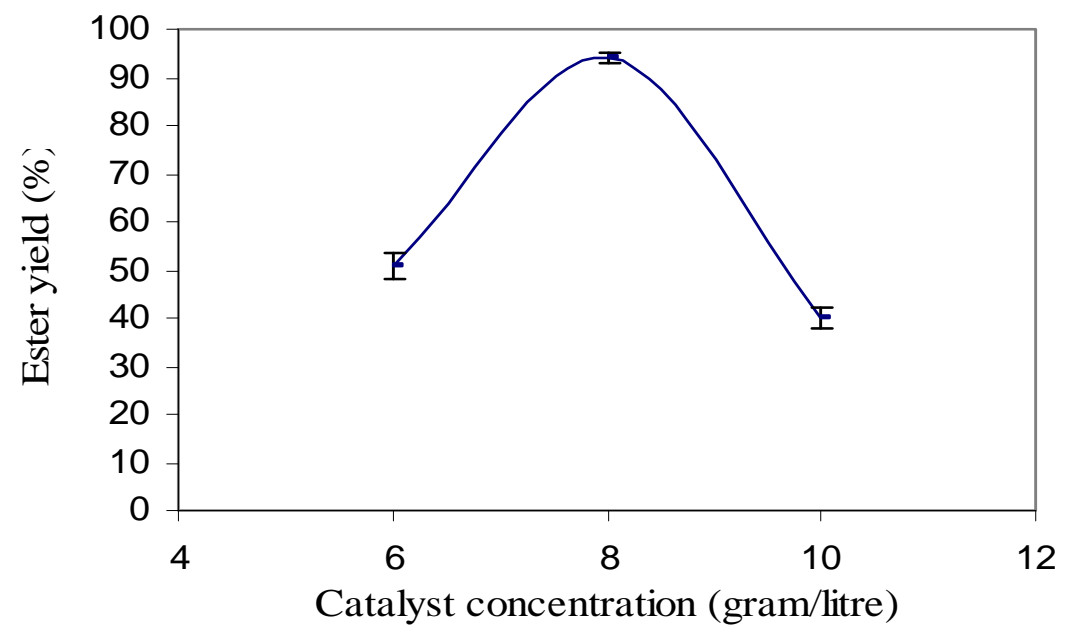

\subsubsection{Fatty Acid Content Analysis}

Fatty acid contents are the major indicators of the properties of biodiesel. Duplicate samples were used to determine the fatty acid content of the biodiesel product. Table 2 shows the summary of fatty acid content in the waste cooking oil. From Gas Chromatography analysis, it was found that the biodiesel derived from the sample of waste cooking oil contains oleic acid (59.7\%) followed by linoleic acid (19.31\%), linolenic acid (6.82\%), palmitic acid (5.18\%), stearic acid (2.1\%), ecosenoic acid (1.21\%) and rest the others (4.36\%). Biodiesel from the sampled waste cooking oil contained the highest amount of oleic acid among other fatty acids in the product and that reported by Issariyakul et al. [17].

In waste cooking oil biodiesel, approximately $60 \%$ of the fatty acids were found to be monounsaturated (C18:1). Poly-unsaturated fatty acids were found to be approximately 26\% (C18:2, C18:3). Only approximately 8\% fatty acids were saturated. Palmitic acid and stearic acid were the major saturated fatty acids found in our waste cooking oil ethyl ester. Over $4 \%$ of the products were unidentified. These values were found from the GC analysis. The amount and type of fatty acid content in the biodiesel are the major factors that determine the viscosity of biodiesel. The qualitative and quantitative analyses of fatty acid content are comparable with the study reported by Issariyakul et al. [17] for waste cooking oils. The amount of oleic acid content in biodiesel from waste cooking oil is comparable with the amount of oleic acid content in peanut oil (53-71\%) as summarized by Allen [21]. 
Table 2. Fatty acid composition of biodiesel from waste cooking oil.

\begin{tabular}{|l|c|c|c|}
\hline $\begin{array}{c}\text { Type of fatty } \\
\text { acids }\end{array}$ & $\begin{array}{c}\text { Carbon } \\
\text { Chain }\end{array}$ & $\begin{array}{c}\text { Experiment, waste } \\
\text { cooking oil, \% }\end{array}$ & $\begin{array}{c}\text { Waste cooking oil as reported } \\
\text { by Issariyakul } \text { et al. [17], \% }\end{array}$ \\
\hline Myristic & C14:0 & 0.11 & 0.41 \\
\hline Palmitic & C16:0 & 5.18 & 8.22 \\
\hline Palmitoleic & C16:1 & 0.51 & 0.89 \\
\hline Stearic & C18:0 & 2.1 & 5.61 \\
\hline Oleic & C18:1 & 59.7 & 48.83 \\
\hline Linoleic & C18:2 & 19.31 & 10.94 \\
\hline Linolenic & C18:3 & 6.82 & 2.68 \\
\hline Arachidic & C20:0 & 0.61 & 0.56 \\
\hline Eicosenoic & C20:1 & 1.21 & 0.97 \\
\hline Lignoceric & C24:0 & 0.08 & 20.89 \\
\hline Others & & 4.36 & \\
\hline
\end{tabular}

Fatty acid chains, particularly, the saturated fatty acid chains, play an important role in determining the cold flow properties of biodiesel fuel. Hilber et al. [22] derived a relationship between the cold flow properties of biodiesel and saturated fatty acid chain content as shown in Figure 3. From the figure, it is seen that, as the content of the saturated fatty acids increases, the cold filter plugging point (CFPP) of biodiesel occurs at higher temperature. The CFPP of animal fats occurs between approximately between $12^{\circ} \mathrm{C}$ to $-1^{\circ} \mathrm{C}$ [22]. If the biodiesel is derived from rapeseed oil, the CFPP is approximately between $-7^{\circ} \mathrm{C}$ to $-12^{\circ} \mathrm{C}$ [22]. Similarly, the CFPP of waste cooking oil which has an average of $10 \%$ saturated fatty acid content, is somewhere between the CFPP of rapeseed and beef tallow. In the present experiment, the saturated fatty acid content of waste cooking oil was approximately $8 \%$ that corresponds to the CFPP value of approximately $-10^{\circ} \mathrm{C}$. Hence, from the CFPP perspective, waste cooking oil which has less saturated fatty acids performs better than animal fats or other oils with higher amount of saturated fatty acid chains.

\subsection{Viscosity and density of waste cooking oil and biodiesel}

High viscosity is the major problem preventing the use of vegetable oils and animal fats directly in diesel engines. The viscosity of the waste cooking oil was determined by using a falling ball viscometer. Triplicate samples were used for the experiments. It was observed that the average viscosity of canola oil sample was measured to be $70 \mathrm{~mm}^{2} / \mathrm{sec}$ at $21^{\circ} \mathrm{C}$. The viscosity of biodiesel ethyl ester measured at $40^{\circ} \mathrm{C}$ was found to be $5.03 \mathrm{~mm}^{2} / \mathrm{sec}$ which was in the range recommended by ASTM. The ASTM standard for biodiesel viscosity is $1.9-6.0 \mathrm{~mm}^{2} / \mathrm{sec}$ at $40^{\circ} \mathrm{C}$.

The density of waste cooking oil measured at $21^{\circ} \mathrm{C}$ was $90 \mathrm{~g} / \mathrm{cm}^{3}$. The density of biodiesel at $15^{\circ} \mathrm{C}$ was found to be $87 \mathrm{~g} / \mathrm{cm}^{3}$. Tate et al. [23] reported that density is a function of temperature and decreased linearly for canola methyl esters, soy methyl esters, and fish oil ethyl esters by $1.23 \mathrm{~kg} / \mathrm{m}^{3}$ ${ }^{\circ} \mathrm{C}$ for temperatures between $20-300^{\circ} \mathrm{C}$. 
Figure 3. Relation between saturated fatty acid chain in biodiesel and its CFPP value [22].

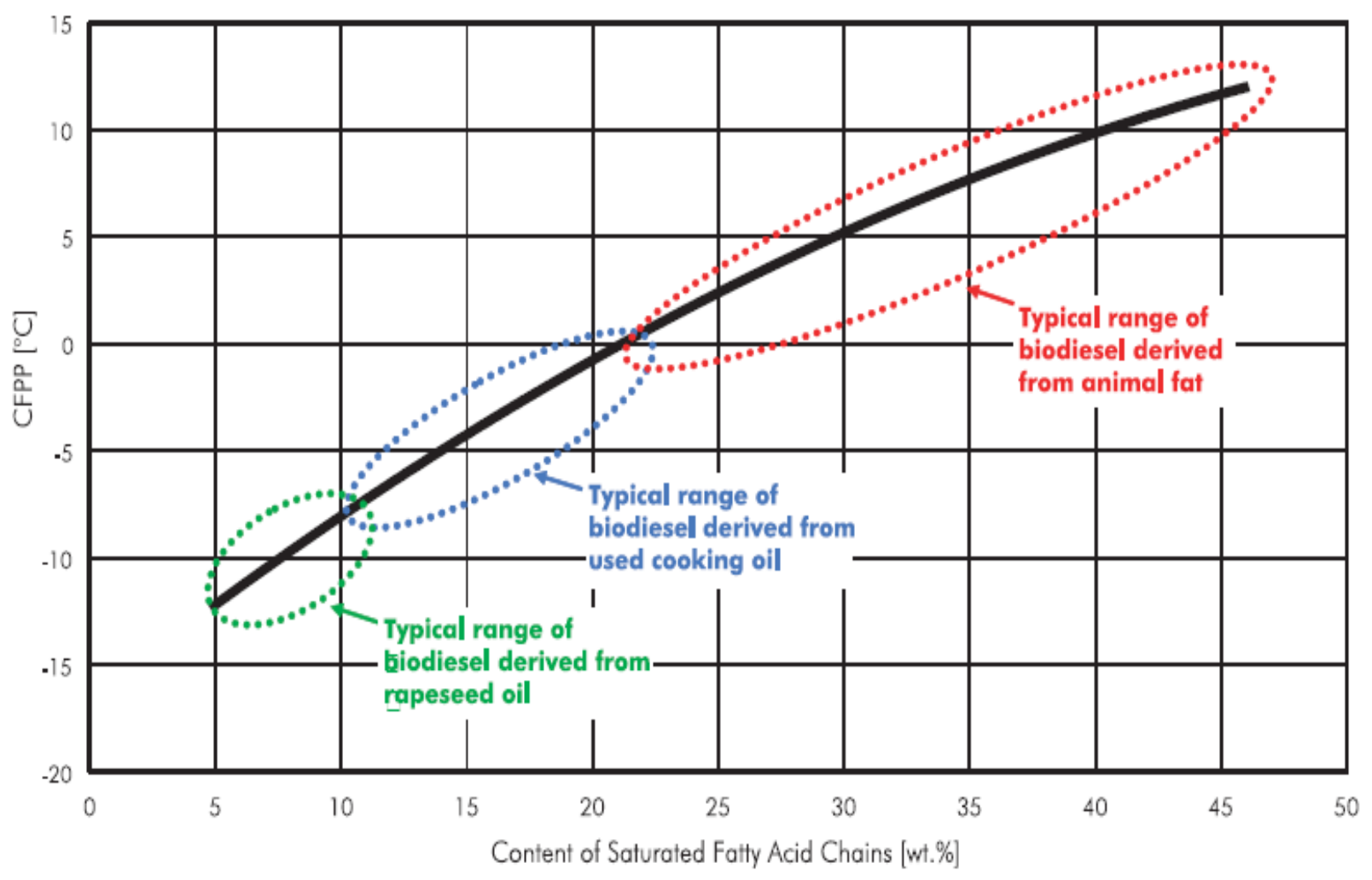

\subsection{Separations of biodiesel and glycerin}

After completion of transesterification, the reaction mixtures were allowed to cool down. After the mixture was cooled down, crude biodiesel and glycerin phases could be seen clearly. This phase separation was seen within few minutes. However, the crude biodiesel was cloudy and opaque. The clear separation was observed after 12-24 hours of settling.

\subsection{Fuel Characterization}

The sample was tested to determine the fuel characteristics according to ASTM Biodiesel Fuel Quality Assurance Standard Test. Table 3 shows the summary of test method used, the standard limit as recommended by ASTM and the test results.

\subsection{Monoglyceride, triglycerides and triglyceride content}

ASTM does not have a standard limit for triglyceride, diglyceride and monoglyceride content in the final product. However, European biodiesel standard (EN14214) recommends that the triglyceride, diglyceride and monoglyceride content should not exceed 0.8, 0.2 and 0.2 , respectively. The experimental results were found to be within the limits of the European Standard. The flashpoint was found to be significantly higher than the minimum standard value. 
Table 3. Fuel Properties of Waste Cooking Oil (WCO).

\begin{tabular}{|c|c|c|c|c|}
\hline Test name & Test Method & $\begin{array}{c}\text { Standard } \\
\text { Limit } \\
\end{array}$ & Result & $\begin{array}{c}\text { European } \\
\text { EN14214 }\end{array}$ \\
\hline Free Glycerin (mass \%) & ASTM D6584 & Max 0.020 & 0.022 & \\
\hline Monoglycerides (mass\%) & ASTM D6584 & NA & 0.293 & 0.8 \\
\hline Diglycerides (mass \%) & ASTM D6584 & NA & 0.19 & 0.2 \\
\hline Triglycerides (mass\%) & ASTM D6584 & NA & 0.061 & 0.2 \\
\hline Total Glycerin (mass\%) & ASTM D6584 & 0.024 & 0.566 & \\
\hline Flash Point, Closed cup $\left({ }^{0} \mathrm{C}\right)$ & ASTM D93 & Min 130 & 164 & \\
\hline Phosphorous (ppm) & ASTM D 4951 & Max 10 & 2 & \\
\hline Calcium+Magnesium (ppm) & EN 14538 & Max 1 & 1 & \\
\hline Sodium+potassium (ppm) & EN 14538 & $\operatorname{Max} 5$ & 66 & \\
\hline Water+Sediment (vol\%) & ASTM D 2709 & Max 0.05 & 0 & \\
\hline Sulfur by UV (ppm) & ASTM D 5453 & $\operatorname{Max} 15$ & 2 & \\
\hline TAN (mgKOH/g) & ASTM D 664 & Max 0.80 & 0.29 & \\
\hline Viscosity@40ㄷ mm²/sec & ASTM D 445 & $1.9-6.0$ & 5.03 & \\
\hline Sim.Dis., $90 \%$ recovery $\left({ }^{0} \mathrm{C}\right)$ & ASTM D 2887 & Max 360 & 366 & \\
\hline Cetane Index & ASTM D 976 & Min 47 & 61 & \\
\hline Cloud Point $\left({ }^{0} \mathrm{C}\right)$ & ASTM D 2500 & NA & -1 & \\
\hline Pour Point $\left({ }^{0} \mathrm{c}\right)$ & ASTM D 97 & NA & -16 & \\
\hline Density @15ํㄷ g/cm³ & - & NA & 0.87 & $0.86-0.90$ \\
\hline
\end{tabular}

\subsection{Total Acid number}

The ASTM standard for total acid number (TAN) for pure biodiesel is $0.8 \mathrm{mgKOH} / \mathrm{g}$. The TAN or acid value is the total amount of potassium hydroxide necessary to neutralize the free acids in biodiesel sample. Lang et al. [24] reported that the acid values of the ethyl esters of linseed oil, canola oil, sunflower oil and rapeseed oil were $0.884,0.869,0.876$ and $0.873 \mathrm{mgKOH} / \mathrm{g}$, respectively. The test result for the TAN for waste cooking oil ethyl ester was found to be 0.29 . This can further be improved by controlling the transesterification, cleaning and drying processes. High TAN or acid values on the feedstock indicates unrefined or poorly refined product oil source due to poor process control, such as ethanol carryover. Higher acid number could also cause degradation of rubber parts in older engines resulting in filter clogging. The total acid number can also be determined by titration.

\subsection{Cloud point and pour point}

The cloud and pour point are also the important properties of biodiesel fuel. Cloud point is the temperature at which a cloud of wax crystals first appear in the oil when it is cooled. The pour point is the lowest temperature at which the oil sample can still be moved. These properties are related to the use of biodiesel in the cold temperature. The cloud point of ethyl ester produced from waste cooking oil was found to be $-1^{\circ} \mathrm{C}$. Lang et al. [24] reported the cloud point of ethyl esters of linseed oil, canola, 
sunflower and rapeseed oil were $-2^{\circ} \mathrm{C},-1^{\circ} \mathrm{C},-1^{\circ} \mathrm{C}$ and $-2^{\circ} \mathrm{C}$, respectively whereas the corresponding methyl esters had cloud point of $0^{\circ} \mathrm{C}, 1^{\circ} \mathrm{C}, 1^{\circ} \mathrm{C}$ and $0^{\circ} \mathrm{C}$. The cloud point of ethyl esters were approximately $2^{\circ} \mathrm{C}$ lower than those of the corresponding methyl esters. This indicates that the ethyl esters marginally perform better in cold temperatures than the corresponding methyl esters. The pour point from waste cooking oil was found to be $-16^{\circ} \mathrm{C}$. As reported by Lang et al. [24], the pour point of ethyl esters of linseed oil, canola, sunflower and rapeseed oil were $-6^{\circ} \mathrm{C},-6^{\circ} \mathrm{C},-5^{\circ} \mathrm{C}$ and $-15^{\circ} \mathrm{C}$ respectively where as the methyl esters of corresponding oils were reported to be $-9^{\circ} \mathrm{C},-9^{\circ} \mathrm{C},-8^{\circ} \mathrm{C}$ and $-15^{\circ} \mathrm{C}$ respectively. Lee et al. [25] argued that the cloud points were affected by the presence of monoglycerides, however, the pour points were not affected. Moreover, the cis double bond present in the erucic acid of rapeseed oil hampered the lowering of the pour point of esters. The type of fatty acid branched chain available in the original oil has an impact on the pour point.

\subsection{Cetane number}

Cetane numbers are the indicators of ignition properties of the diesel fuel. The higher the cetane number, the more efficient the ignition is. Because of the higher oxygen content, biodiesel has a higher cetane number compared to petroleum diesel.

Cetane number of the diesel fuel is the indicator of the ignition quality. The cetane index of waste cooking oil from experiment was found to be 61. Hilber et al. [22] reported the cetane number of methyl esters of rapeseed oil, soybean oil, palm oil, lard and beef tallow to be 58, 53, 65, 65 and 75 respectively. Among these biodiesel feedstocks, beef tallow has the highest cetane number. The higher cetane number indicates the higher engine performance of beef tallow compared to other fuels, resulting in lower emission of all pollutants other than oxides of nitrogen (NOx). As beef tallow has the higher amount of saturated fatty acids, the increase in the saturated fatty acids content positively enhanced the cetane number of biodiesel. The oxidative stability of biodiesel fuels also increases due to the presence of higher amount of saturated fatty acids. However, the drawback of higher amount of saturated fatty acid content in biodiesel fuel is that the cold filter plugging point occurs at a higher temperature.

\subsection{Water and sediment}

In this experiment, it was found that there was no water and sediment content in the sample. A rotary evaporator was used to drive off the water and any remaining alcohol. The complete removal of water and unreacted alcohol was determined when the constant weight was achieved during the rotary evaporation. The ASTM standard limit for water and sediment was is $0.05 \%$ by volume of the sample.

\subsection{Total and free glycerin, sodium and potassium and simulated distillation}

Out of 18 fuel properties tested, four of them slightly exceeded the ASTM standard limit. It was found that free glycerin, total glycerin, sodium and potassium and simulated distillation for $90 \%$ recovery did not meet the requirement. The major reasons for this could be due to insufficient washing and improper separation of biodiesel and glycerin phase. The $\mathrm{pH}$ of the sample was measured and found to be 9.6 , which indicates the presence of catalyst residue in the sample. The remaining catalysts 
could be completely removed by using hot distilled water wash [17]. Kemp [15] recommended that higher quality and speedy washing can be achieved by employing hot wash water at temperatures between $50-60^{\circ} \mathrm{C}$. Moreover, increasing the number of washes is necessary to remove all catalyst until the $\mathrm{pH}$ of the biodiesel is 7.0.

The $\mathrm{pH}$ was lowered down to 7 by increasing the number of washes. Higher number of washes could also help to reduce the amount of free glycerin in the samples. Issariyakul et al. [17] reported that the glycerin phase in the case of waste cooking oil is difficult to separate only by gravity. Hence, they suggested that total and free glycerin can be completely removed by adding pure glycerin so that all the glycerin settles down with pure glycerin. The distillation test result (Table 2) could have been affected due to the presence of total and free glycerin. Glycerin has the higher density necessitating the higher temperature for the distillation of biodiesel sample. By improving the ester purification, the simulated distillation may also meet the ASTM standard.

Figure 4. Distribution of biodiesel production costs, \% [15] .

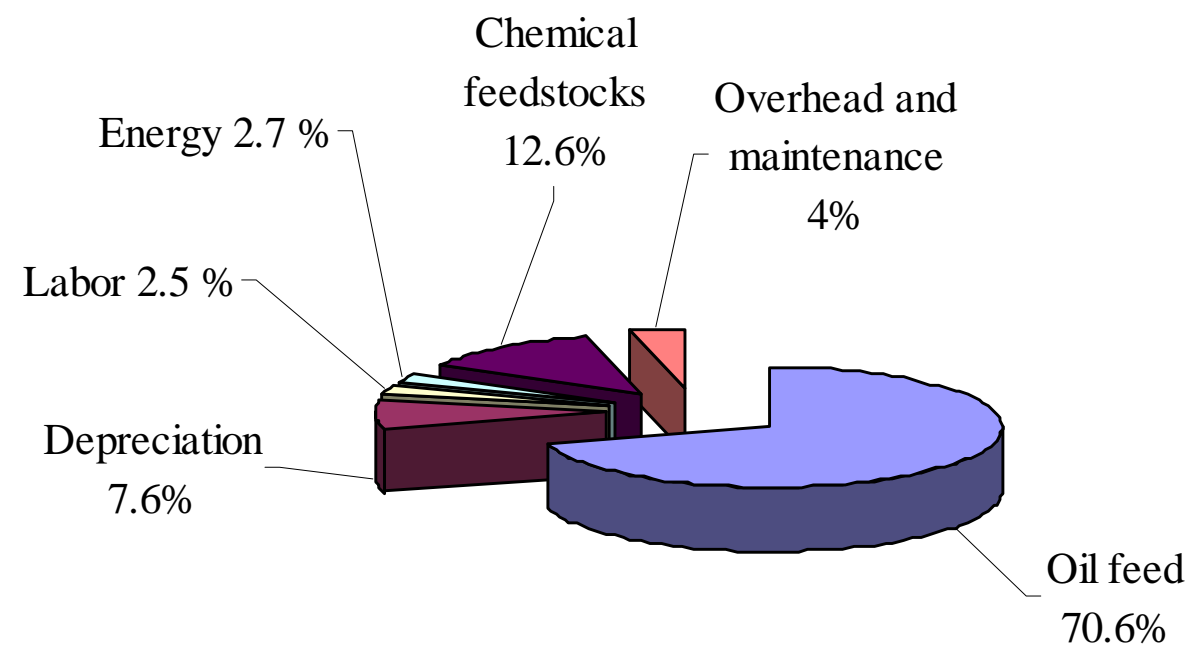

\subsection{Economics of Biodiesel from Waste Cooking Oil}

The economics of biodiesel production have taken a new turn with the current surge in crude oil price in the world market. BBC [26] recently reported that the crude oil price set a fresh new record level at \$109 per barrel. The diesel price in the US is close to \$4 per gallon [27]. As the oil prices increase in the international market, biodiesel could become a more viable alternate energy source. Kemp [15] reported the distribution of biodiesel production costs as shown in Figure 4. Oil feedstock cost is the major cost of biodiesel production accounting over $70 \%$ of the total costs. Hence, if the waste vegetable oil is used as biodiesel feedstock, the economics of biodiesel can be significantly improved. Moreover, the use of waste cooking oil also reduces the waste treatment costs. In many parts of the world, there are no legislations that ban the disposal of waste cooking oil into the drainage system. Disposal of waste cooking oil into the drains creates several operation and maintenance problems. The disposed oil can solidify thereby blocking the drainage systems and also pollutes 
sewage and waterways [28]. The cost of sewage treatment with high lipid content could be high. The restaurants, at the same time, do not need to spend money to transport the waste cooking oil to discharge into specific locations. The municipalities involved in the sewage treatment could spend less money for sewage treatment if the lipid content in the sewage is low. Hence, recycling of waste cooking oil to produce biodiesel will increase the cost of waste treatment.

\section{Conclusions}

The ethyl ester was prepared from waste cooking oil sample collected from a local restaurant in Halifax. The fatty acid composition of final biodiesel esters was determined by gas chromatography and found that the waste cooking oil contains mainly oleic acid in the final products. This is because the original oil used was found to be canola oil. The biodiesel was characterized for its physical and fuel properties using ASTM standard methods for biodiesel fuel quality assurance. From the tests, the flash point was found to be $164^{\circ} \mathrm{C}$, the phosphorous was $2 \mathrm{ppm}$, calcium and magnesium was $1 \mathrm{ppm}$ together, water and sediment was $0 \%$, sulfur content was $2 \mathrm{ppm}$, total acid number was 0.29

$\mathrm{mgKOH} / \mathrm{g}$, viscosity at $40^{\circ} \mathrm{C}$ was $5.02 \mathrm{~mm} / \mathrm{sec}$, cetane index was 61 , cloud point was $-1^{\circ} \mathrm{C}$ and pour point was $-16^{\circ} \mathrm{C}$. Out of 18 properties tested, 14 of them met the ASTM criteria for fuel standard. The reasons why the tests failed have been explained and measures are suggested to improve the overall process to produce biodiesel of ASTM fuel quality standard. Production of biodiesel from waste cooking oils for diesel substitute is particularly important because of the decreasing trend of economical extracted oil reserves and the environmental problems caused due to the use of fossil fuel. Waste cooking oil can be an important source for biodiesel production in Canada as there is large quantity of waste cooking oil available. Use of waste cooking oil helps improve the biodiesel economics.

\section{Materials and Methods}

It is recognized that the production of waste cooking oil will be the function of the frying temperature and length of use as well as the material used for frying. In this experiment, waste cooking oil was collected from a local restaurant (Tajmahal Restaurant) in Halifax, which serves fast food as well as continental foods. The oil used for cooking was pure canola oil. The used oil sample was taken from the fryer which is used for frying potatoes and other vegetables based food items. Four litters of oil samples were collected from a collecting drum in which the waste cooking oil was dumped once in every two days for approximately 2-3 weeks. The oil sample is assumed to be representative as it is collected from the oil stored for 2-3 weeks from several batches of waste oil. The temperature observed during frying was in the range of $130^{\circ} \mathrm{C}$ to $175^{\circ} \mathrm{C}$. This temperature is comparable with the temperature $\left(140^{\circ} \mathrm{C}-180^{\circ} \mathrm{C}\right)$ for preparing French fries reported by Rywotycki [16]. The temperature was recorded by a REED ST-883 high temperature infrared thermometer that can measure temperature in the range of $-50^{\circ} \mathrm{C}$ to $700^{\circ} \mathrm{C}$. The temperature range was recorded at three different times in a day. However, it was found difficult to read the temperature in boiling oil which gives approximately 5$10 \%$ error. Depending on the quantity of food used for frying, the oil was discarded sometimes at the end of each day and sometimes once in two or three days. 
Sodium hydroxide was used as catalyst in this experiment. The amount of catalyst had an impact in the conversion of esters during the transesterification process. The titration was carried out in order to determine the optimum amount of catalyst concentration of for efficient transesterification. The titration result showed that for the particular waste cooking oil, the optimum catalyst concentration was $0.08 \%$ by weight. The reaction was carried out using $0.4 \%, 0.6 \%, 0.8 \%, 1.0 \%$ and $1.2 \%$ of catalyst concentration.

The oil sample was heated in a beaker to $110^{\circ} \mathrm{C}$ to evaporate the water. The oil was filtered using a cloth (75 microns) to separate any particles. In order to determine the amount of catalyst needed for transesterification, titration was carried out using a standard $\mathrm{NaOH}$ solution $(0.1 \%)$ because sodium hydroxide was used as the catalyst in this process. From the titration, the total amount of catalyst per liter of waste cooking oil was determined to be 8 grams of $\mathrm{NaOH}$ per liter of waste cooking oil. This amount was confirmed to be correct by actual experiment.

The transesterification reaction was carried out using $100 \%$ technical grade ethyl alcohol. The alcohol used was $280 \mathrm{~mL}$ per liter of waste cooking oil. First the alcohol and catalyst mixture and oil were heated separately to $50^{\circ} \mathrm{C}$. Then both were poured into the reactor vessel in which the reaction was to be carried out. Transesterification was carried out using a heating plate and a magnetic stirrer. The reaction temperature used was $60^{\circ} \mathrm{C}$. The average reaction time observed was 20 minutes. This was determined by taking samples after every 5, 10, 15, 20 and 25 minutes. After heating at $60^{\circ} \mathrm{C}$ for 20 minutes, the mixture was cooled in air for about 24 hours at room temperature $\left(24^{\circ} \mathrm{C}\right)$ to settle the glycerin phase and biodiesel phase by gravity. Most of the excess alcohol and catalyst were contained in the glycerin phase. The biodiesel samples (ethyl esters) were collected and stored in a refrigerator for further analysis in a GC.

Lipid composition was determined using thin-layer chromatography with FID on the IATROSCAN TH-10 Analyzer MKIII. Each biodiesel sample was dissolved in chloroform and applied to a chromatod. The chromarods were then developed in a tank containing a 48:48:4:1 hexane-petroleum ether-diethyl ether-formic acid solvent system for 25 minutes. After developing they were oven dried and then scanned until just after the phospholipid peaks, lipids were identified by comparison of retention times to that of pure standards. Data were analyzed with Peak Simple Chromatography software. The percent area, uncorrected for differential response of lipids, was used to calculate the lipid content as weight percent of total.

In order to prepare the sample for GC analysis, the ethyl esters were converted to fatty acid methyl esters (FAME) by acid catalyzed transesterification. The fatty acid ethyl ester sample was converted to FAME because the column available in GC was for FAME. After the analysis, a correction factor was applied to convert the FAME to ethyl ester. $\mathrm{H}_{2} \mathrm{SO}_{4}$ in methanol $(0.5 \mathrm{~N})$ was used to produce FAME [29]. FAME were characterized using gas chromatography (GC) with flame ionization detection (FID) using a 50\% cyanopropyl polysiloxane phase (Agilent Technologies, DB-23; $30 \mathrm{~m}$ x 0.25 mm ID). Helium was used as the carrier gas and the gas line was equipped with an oxygen scrubber. The following temperature program was employed: $153{ }^{\circ} \mathrm{C}$ for $2 \mathrm{~min}$, held at $174{ }^{\circ} \mathrm{C}$ for 0.2 min after ramping at $2.3{ }^{\circ} \mathrm{C} \mathrm{min}^{-1}$ and held at $220{ }^{\circ} \mathrm{C}$ for $3 \mathrm{~min}$ after ramping at $2.5{ }^{\circ} \mathrm{C} \mathrm{min}{ }^{-1}$. FAME was reported as weight percent of total fatty acids (FA). Each FA was described using the shorthand nomenclature of $\mathrm{A}: \mathrm{Bn}-\mathrm{X}$, where $\mathrm{A}$ represents the number of carbon atoms, $\mathrm{B}$ the number of double bonds and $\mathrm{X}$ the position of the double bond closest to the terminal methyl group. 
Alkali catalyzed transesterification process was used for this work. The reaction was carried out on a single stage batch reactor (Figure 5). The reactor used was a $500 \mathrm{ml}$ glass beaker in a heating plate with magnetic stirrer for mixing. Figure 6 shows two phase of biodiesel ester and glycerin layer. The complete separation was achieved after 20 hours.

Figure 5. Glass reactor with heating plate and magnetic stirrer.

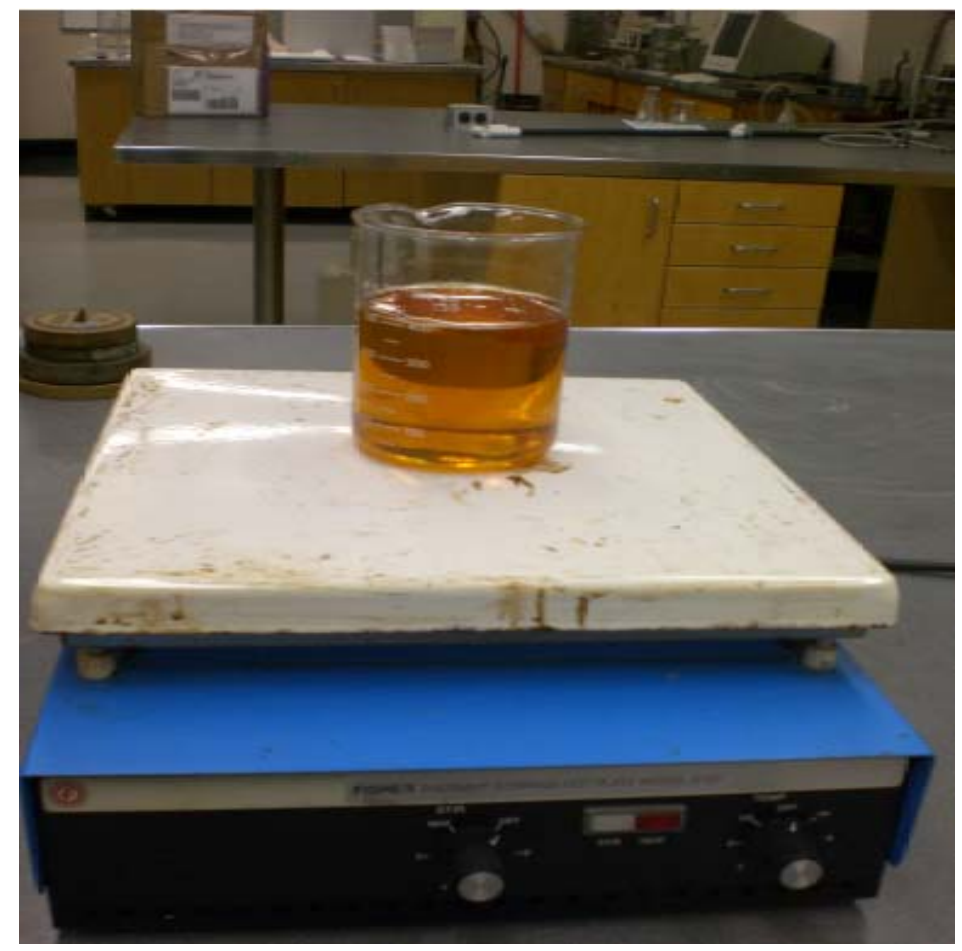

Figure 6. Biodiesel ester and glycerin layer.

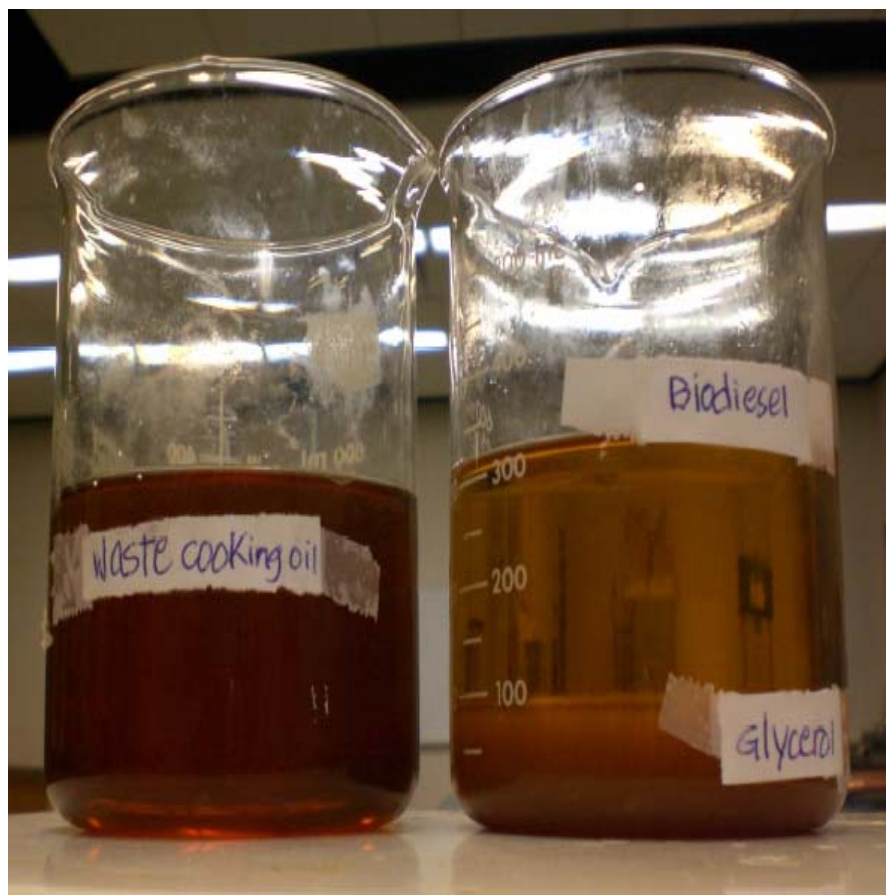


Figure 7 shows the glycerin biodiesel separation by gravity method. The biodiesel was separated in another vessel for washing. It was washed using a separating funnel creating a fine mist of water from the top (Figure 8).

Figure 7. Biodiesel using $\mathrm{NaOH}$ catalysts.

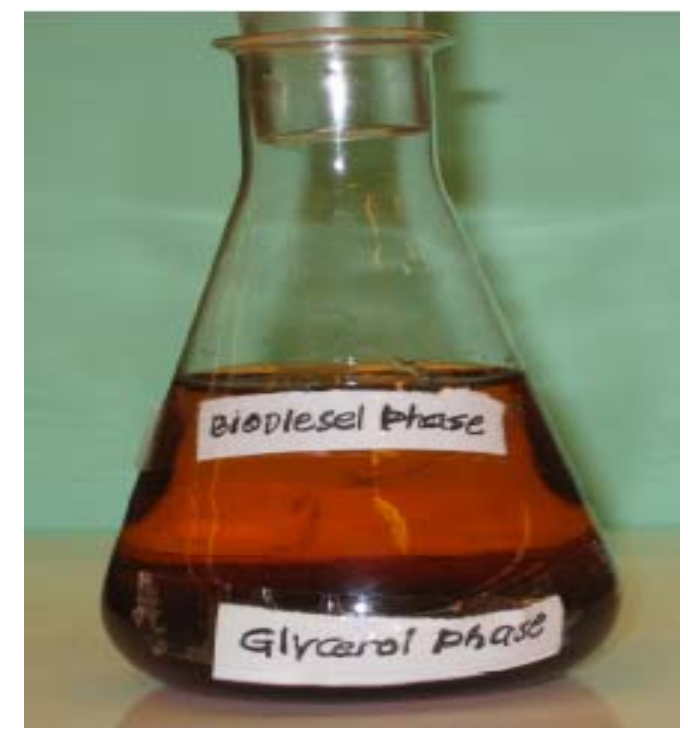

Figure 8. Biodiesel washing using distilled water.

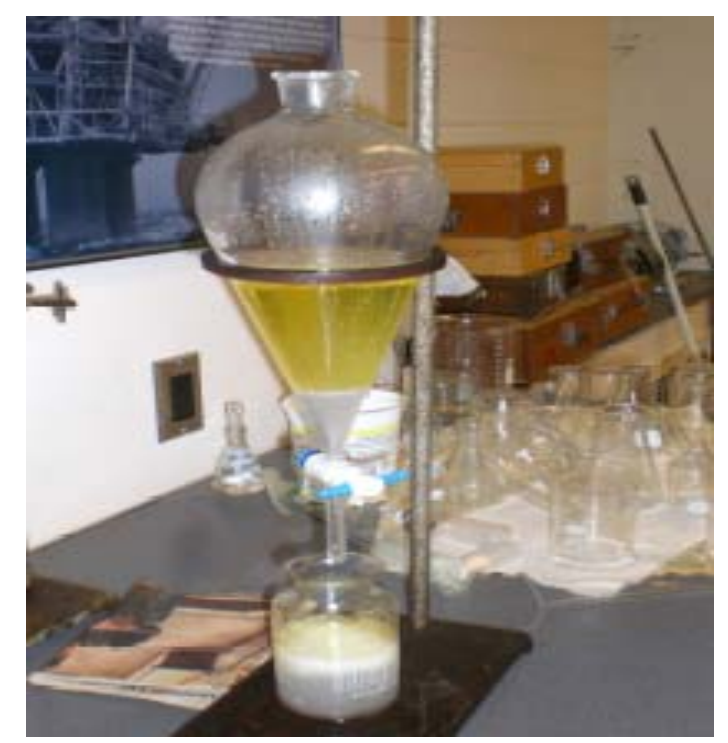

The ethyl ester samples were sent to the Bently Tribology Services Inc., 1711 Orbit Way, Building 2, Minden, Nevada, USA for fuel characterization. The fuel properties were tested according to the ASTM Biodiesel Fuel Quality Assurance Standard Test standards. 


\section{Acknowledgements}

The first and last author would like to acknowledge Atlantic Innovation Fund and NSERC discovery grant for funding this project. The authors would like to thank Dr. S.M. Budge for providing laboratory facilities and Anne Timmins for her assistance during the laboratory analyses.

\section{References}

1. Lean, G. Oil and gas may run short by 2015. The Independent, UK. 2007. http://environment.independent.co.uk/climate_change/article2790960.ece, (Accessed on 23 July 2007).

2. Demirbas, A. Biofuels from Vegetable Oils via Catalytic and Non-Catalytic Supercritical alcohol Transesterifications and Other Methods: A Survey. Energy Convers. Manage. 2003, 44, 2099-109.

3. Kurki, A.; Hill, A.; Morris, M. Biodiesel: The sustainability dimensions. ATTRA Publication \#IP281, 2006, 1-12. http://attra.ncat.org/attra-pub/PDF/biodiesel_sustainable.pdf (accessed on 27 October 2007).

4. Khan, M.I.; Chhetri, A.B.; Islam, M.R. Analyzing Sustainability of Community Based Energy Technologies. Energy Sources 2007, 2, 403-419.

5. Canakci, M. The Potential of Restaurant Waste Lipids as Biodiesel Feedstocks. Bioresource Technology 2007, 98, 183-190.

6. Roger, A.K.; Jaiduk, J.O. A rapid engine test to measure injector fouling in diesel engines using vegetable oil fuels. J. Am. Oil Chem. Soc. 1985, 62(11), 1563-4.

7. Connemann, J.; Fischer, J. Biodiesel in Europe 1998: biodiesel processing technologies. Paper presented at the International Liquid Biofuels Congress, Brazil, 1998, 1-16.

8. Radich, A. Biodiesel performance, costs, and use. US Energy Information Administration, 2006. http://www.eia.doe.gov/oiaf/analysispaper/biodiesel/index.html.

9. Statistics Canada. Canada’s Population Clock. Statistics Canada, Demography Division, 2006. Updated in 27 October 2006.

10. Kulkarni, M.G.; Dalai, A.K. Waste Cooking Oils an Economical Source for Biodiesel: A Review. Ind. Eng. Chem. Res. 2006, 45, 2901-2913.

11. Carter, D.; Darby, D.; Halle, J.; Hunt, P. How To Make Biodiesel; Low-Impact Living Initiative, Redfield Community, Winslow, Bucks, 2005, ISSN 0-9649171-0-3.

12. Yang, H-H.; Chien, S-M.; Lo, M-Y.; Lan, J.C.-W.; Lu, W-C.; Ku, Y-Y. Effects of biodiesel on emissions of regulated air pollutants and polycyclic aromatic hydrocarbons under engine durability testing. Atmospheric Environment 2007, 41, 7232-7240.

13. Klass, L.D. Biomass for Renewable Energy, Fuels and Chemicals; Academic Press: New York, 1998; pp. 1-2.

14. Holbein, B.E.; Stephen, J.D.; Layzell, D.B. Canadian Biodiesel Initiative: Aligning Research Needs and Priorities With the Emerging Industry Final Report; Biocap Canada, Kingston, Ontario, Canada, 2004; pp. 1-35.

15. Kemp, W.H. Biodiesel basics and beyond. A comprehensive guide to production and use for the home and farm. Aztext Press: Ontario, Canada, 2006. 
16. Rywotycki, R. The effect of fat temperature on heat energy consumption during frying of food. Journal of Food Engineering 2002, 54, 257-261.

17. Issariyakul, T.; Kulkarni, M.G.; Dalai, A.K.; Bakhshi, N.N. Production of biodiesel form waste fryer grease using mixed methanol/ethanol system. Fuel Processing Technology 2007, 88, 429436.

18. Leung, D.Y.C.; Guo, Y. Transesterification of neat and used frying oil: optimization for biodiesel production. Fuel processing Technology 2006, 87, 883-890.

19. Zheng, S.; Kates, M.; Dube, M.A.; McLean, D.D. Acid-catalyzed production of biodiesel from waste frying oil. Biomass and Bioenergy 2006, 30, 267-272.

20. Attanatho, L.; Magmee, S.; Jenvanipanjakil, P. The Joint International Conference on 'Sustainable Energy and Environment', 1-3 December 2004, Huan Hin, Thailand.

21. Allen, C.A.W. Prediction of Biodiesel Fuel Atomization Characteristics Based on Measured Properties. Ph.D. Thesis, Faculty of Engineering, Dalhousie University. 1998.

22. Hilber, T.; Mittelbach, M.; Schmidt, E. Animal fats perform well in biodiesel. Render 2006, 1618. http://www.rendermagazine.com/pages/pastarticles2006.html (accessed on 30 Aug 2006).

23. Tate, R.E.; Watts, K.C.; Allen, C.A.W.; Wilkie, K.I. The densities of three biodiesel fuels at temperatures up to $300^{\circ} \mathrm{C}$. Fuel 2006, 85, 1004-1009.

24. Lang, X.; Dalai, A.K.; Bakhsi, N.N.; Reaney, M.J.; Hertz, P.B. Preparation and characterization of bio-diesels from various bio-oils. Bioresource Technology 2001, 80, 53-62.

25. Lee, I.; Johnson, L.A.; Hammond, E.G. Use of branched-chain esters to reduce the crystallization temperature of biodiesel. JAOCS 1995, 72, 1155-1160.

26. BBC. Oil sets fresh record above $\$ 109$, 2008, http://news.bbc.co.uk/2/hi/business/7289070.stm.

27. EIA. Short-Term Energy Outlook. 2008, http://www.eia.doe.gov/emeu/steo/pub/contents.html (Accessed on 11 March 2008).

28. Stevens, A. Waste Vegetable Oil Recycling for Bio-diesel Production in Essex \& Cambridgeshire. Wastewise Overview Report 2 May 2003. Anglia Polytechnic University Ashby House, Bishop Hall Lane, Chelmsford CM1 1SQ. http://www.ecorrn.org.uk/pdf/Biodiesel.pdf (Accessed on 8 April 2008)

29. Budge, S.M.; Iverson, S.J.; Koopman, H.N. Studying trophic ecology in marine ecosystems using fatty acids: A primer on analysis and interpretation. Marine Mammal Science 2006, 22, 759-801.

(C) 2008 by the authors; licensee Molecular Diversity Preservation International, Basel, Switzerland. This article is an open-access article distributed under the terms and conditions of the Creative Commons Attribution license (http://creativecommons.org/licenses/by/3.0/). 